\title{
OVERVIEW OF THE NOAA/ESRL FEDERATED AEROSOL NETWORK
}

Elisabeth Andrews, Patrick J. Sheridan, John A. Ogren, Derek Hageman, Anne Jefferson, Jim Wendell, Andrés Alástuey, lucas Alados-Arboledas, Michael Bergin, Marina Ealo,

A. Gannet Hallar, András Hoffer, Ivo Kalapov, Melita Keywood, Jeongeun Kim, Sang-Woo Kim, Felicia Kolonjari, Casper labuschagne, Neng-Huel lin, AnneMarie Macdonald, Olga L. Mayol-Bracero, Ian B. McCubbin, Marco Pandolfi, Fabienne Reisen, Sangeeta Sharma, James P. Sherman, Mar Sorribas, and Junying Sun

The cooperative nature of NOAA's Federated Aerosol Network allows for collection of consistent datasets for evaluating regionally representative aerosol climatologies, trends, and radiative forcing at 30 sites around the world.

C limate change is one of the most important environmental, social, economic, and political issues facing the planet today. Aerosol particles may have either a warming or cooling effect at the top of the atmosphere, depending on both the properties of the aerosol and the underlying surface (IPCC 2013). Atmospheric aerosol particles interact with solar radiation by absorbing and scattering light. The amount of scattering and absorption is a function of particle size, composition, and shape, as well as external variables like relative humidity $(\mathrm{RH})$ and the wavelength of incident light. The regional influence of aerosol particles on climate and weather tends to be stronger than their global average impact, because of their relatively short atmospheric lifetimes and inhomogeneity in sources and processing. Thus, to understand the global influence of aerosol particles, it is necessary to make long-term measurements at many regionally representative sites (e.g., Laj et al. 2009; Lund Myhre and Baltensperger 2012). Shortterm aerosol campaign measurements are typically designed to study specific processes and/or events; however, long-term measurements are often needed to put such data into a broader context, for example, to assess whether field campaign measurements represent that location and season, and to assess trends and variability. Such long-term measurements can take the form of ground-based remote sensing, satellite-based remote sensing, and/or ground-based in situ sites. While the focus here is on long-term surface in situ sites, it is important to recognize the synergy obtained when data from multiple independent platforms are combined (e.g., Ogren 1995; Kahn et al. 2004, 2017; Anderson et al. 2005). For example, combining surface measurements with airborne or remote sensing platforms enables the connection of ground-based aerosol properties to vertically resolved processes. While ground-based in situ measurements cannot represent the properties of aerosols that are present in layers aloft, multiyear in situ aerosol profiling measurements over two Federated Aerosol Network (FAN) sites in the United States have 
shown that ground-based measurements of aerosol intensive properties such as the single-scattering albedo and the scattering Ångström exponent can represent the climatology of those properties aloft under well-mixed conditions (Andrews et al. 2004; Sheridan et al. 2012).

Numerous stations around the world make longterm in situ measurements of regionally representative aerosol optical properties. Originally, many of these sites were operated in isolation to address specific scientific goals with sampling and data protocols designed to meet those goals, making it difficult to utilize those data in wider studies and intercomparisons (Kulmala et al. 2011). Several recent papers note the importance of consistent operational and data processing among sites in order to improve data quality control and access across locations (e.g., Kulmala et al. 2011; Wiedensohler et al. 2012). In contrast, some sites (e.g., the original NOAA baseline observatories; Bodhaine 1983) were conceived as part of a network where similarities in instruments, protocols, and a common data archive resulted in complete intranetwork consistency, although extra-network comparisons were limited by differences in data collection and/or treatment. Recognition of the need for consistent measurements drives the development of protocols for instruments and data treatment (e.g., WMO 2016).

This paper presents a description of the current NOAA FAN, which evolved from the original NOAA baseline network. The two primary purposes of this paper are 1) to describe the current state of the FAN (including its member stations, the measurements common to most of the stations, and the sampling and measurement protocols) and 2) to show examples of the science that is possible with a global network of this type. A number of earlier papers (e.g., Sheridan et al. 2001; Delene and Ogren 2002; Sherman et al. 2015) touched on some aspects of this, utilizing small subsets of the network (one to four stations), but, until now, there have been no papers describing the FAN in its entirety. The paper begins with a brief history of the network, discusses the key measurements and measurement protocols made at network sites, describes the software for data acquisition and processing, and, finally, presents an overview of the scientific results from FAN measurements over the last 15 years.

HISTORY OF THE NOAA FAN. The current network mission is to characterize the means, variability, and trends of climate-forcing properties of different types of aerosols, and to understand the factors that control these properties. In the 1970s, NOAA's Environmental Research Laboratory (ERL) Geophysical Monitoring for Climatic Change (GMCC) program had the mission to detect changes (i.e., trends, cycles) in the long-term global aerosol background values. To do so, GMCC conducted aerosol measurements at
AFFILIATIONS: ANDREWS, HAGEMAN, AND JefFERSON-Cooperative Institute for Research in Environmental Sciences, University of Colorado Boulder, Boulder, Colorado; SHERIDAN, OGREN, AND WeNDELLNational Oceanic and Atmospheric Administration/Earth System Research Laboratory, Boulder, Colorado; Alastuey, EAlo, AND PANDOLFI-Institute of Environmental Assessment and Water Research, Barcelona, Spain; AlADOS-ARBoledAs-Instituto Interuniversitario de Investagación del Sistema Terra en Andalucía, Centro Andaluz de Medio Ambiente (CEAMA), University of Granada, Granada, Spain; BERGIN—Department of Civil and Environmental Engineering, Duke University, Durham, North Carolina; HaLLAR-Department of Atmospheric Science, University of Utah, Salt Lake City, Utah, and Storm Peak Laboratory, Desert Research Institute, Steamboat Springs, Colorado; McCuBBIN-Storm Peak Laboratory, Desert Research Institute, Steamboat Springs, Colorado; Hoffer-MTA-PE Air Chemistry Research Group, University of Pannonia, Veszprém, Hungary; KALAPOV—Basic Environmental Observatory Moussala, Institute for Nuclear Research and Nuclear Energy, Sofia, Bulgaria; KEYWOOD AND REISEN-CSIRO Oceans and Atmosphere, Aspendale, Victoria, Australia; J. KıM-Environmental Meteorology Research Division, National Institute of Meteorological Sciences, Seogwipo-si, Jeju-do, South Korea; S.-W. KIM-School of Earth and Environmental Sciences, Seoul National University, Seoul, South Korea; KolonjarI, MACDONALD, AND SHARMA-Environment and Climate Change Canada,
Toronto, Ontario, Canada; LABUSCHAGNE-Climate Environmental Research Monitoring, South African Weather Service, Stellenbosch, South Africa; LIN-Department of Atmospheric Sciences, National Central University, Taoyuan, Taiwan; MAYOL-BraCERo-Department of Environmental Sciences, University of Puerto Rico, Río Piedras Campus, San Juan, Puerto Rico; SHerman-Department of Physics and Astronomy, Appalachian State University, Boone, North Carolina; SORRIBAS-El Arenosillo Atmospheric Sounding Station, Atmospheric Research and Instrumentation Branch, National Institute for Aerospace Technology, Huelva, Spain; SuN-State Key Laboratory of Severe Weather, and Key Laboratory of Atmospheric Chemistry, Chinese Academy of Meteorological Sciences, China Meteorological Administration, Beijing, China

\section{CORRESPONDING AUTHOR: Elisabeth Andrews,}

betsy.andrews@noaa.gov

The abstract for this article can be found in this issue, following the table of contents.

DOI:10.II75/BAMS-D-17-0175.I

A supplement to this article is available online (10.II75/BAMS-D-17-0175.2)

In final form 19 June 2018

(02019 American Meteorological Society

For information regarding reuse of this content and general copyright

information, consult the AMS Copyright Policy. 
four baseline observatories. The original NOAA baseline observatories [Mauna Loa, Hawaii (MLO), the South Pole (SPO), American Samoa (SMO), and Barrow, Alaska (BRW)] appear along the left-hand side of Fig. 1. These sites are remote from aerosol sources and typically represent clean background air; although, occasionally, they may be impacted by long-range transport (e.g., Perry et al. 1999; Stone et al. 2007).

Since the initial founding of the baseline observatory network, the scientific understanding of the prop-

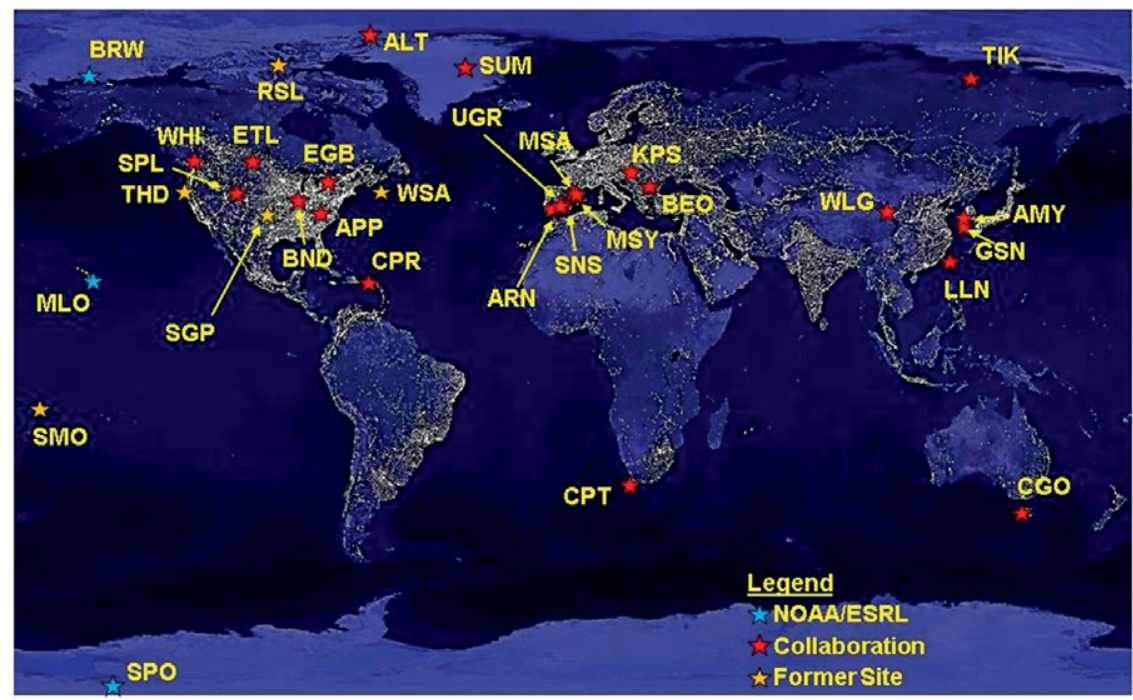

Fig. I. Map of current (January 2018) and former long-term sites in the FAN superimposed on a nighttime lights image (Credit: NASA Earth Observatory and NOAA). Former sites Resolute Bay in Canada (RSL), SGP, and WSA were FAN collaborations, while THD and SMO were solely NOAA observations.

erties and impacts of atmospheric aerosols has improved considerably. In response to the finding that anthropogenic aerosols create a significant perturbation in the Earth's radiative balance on regional scales (e.g., Bolin and Charlson 1976; Charlson et al. 1991), NOAA expanded its aerosol research program starting in 1992 to include four sites in North America: Bondville, Illinois (BND; a collaboration with University of Illinois); Sable Island, Nova Scotia, Canada (WSA; a collaboration with Environment and Climate Change Canada); Southern Great Plains (SGP; a collaboration with the U.S. Department of Energy); and Trinidad Head, California (THD). These site locations were chosen because they are at times impacted by anthropogenic aerosols and consequently address the need to better understand how human activity can influence the radiation balance. Although these sites are not as remote as the baseline observatories, they also are not close to major anthropogenic aerosol sources (e.g., Delene and Ogren 2002) and typically provide measurements of regionally representative aerosol (e.g., Wang et al. 2018).

The NOAA/ESRL/Global Monitoring Division (GMD)'s expertise in maintaining long-term measurements of aerosol optical properties (often at remote locales) did not go unnoticed. Colleagues from around the world contacted GMD for advice on station operations and instrument maintenance, and the collaborative NOAA/ESRL Federated Aerosol Network was born. The concept for and, indeed, the name of the FAN owe much to the development of the Aerosol Robotic Network (AERONET) sunphotometer network in the mid-1990s (Holben et al. 1998). The definition of a federation is groups "that have joined together for a common purpose" (www.collins dictionary.com/us/dictionary/english/federated). The descriptor federated is appropriate, as the result is a long-term cooperative program with shared data access, making atmospheric measurements that are directly comparable with all the other FAN stations. FAN collaborators contribute scientific interest, instruments, on-site technicians, long-term station costs, and operations support, while NOAA contributes software for data acquisition and processing, as well as technical expertise. It is a true partnership, where both sides are learning from each other. A major advantage is that the NOAA software and protocols streamline data acquisition and processing (discussed below) so that more time can be spent on science. Since 2010, more than 50 papers using FAN data have been published (NOAA 2018a) and multiple graduate theses have also been submitted. FAN support has also improved data submission to the World Data Centre for Aerosols (www.gaw-wdca.org), in terms of both quantity of data submitted and quality and completeness of the submitted datasets.

Since 2004, 25 sites operated by numerous collaborators have joined FAN (prior to 2004 only 6 sites were in the network: NOAA's four baseline observatories and two regional stations running NOAA instruments and supervised by NOAA scientists). Many of these new cooperative aerosol monitoring sites are situated in regions where significant aerosol forcing is anticipated, including locations in North America, 
Europe, and Asia. Figure 1 illustrates that, while there is reasonable global coverage, there are also some large spatial gaps (particularly in the Southern Hemisphere) as a result of finite funding resources and limited infrastructure, as well as the lack of collaborators in those regions. NOAA has as major partners in these global and regional aerosol measurements the World Meteorological Organization (WMO)'s Global Atmosphere Watch (GAW) program, and several U.S. and foreign universities and science agencies. Most of the collaborative stations are run under the auspices of the GAW network; thus, FAN sites may be considered a substantial subset of the larger GAW surface in situ aerosol monitoring network (FAN data comprise approximately one-third of GAW's surface aerosol optical property measurements and dominate contributions of optical properties to GAW outside of Europe). Table ES1 in the online supplemental material (https://doi.org/I0.II75/BAMS-D-17-0175.2) provides more detail about the sites shown in Fig. 1.

DESCRIPTION OF SYSTEM. The basic aerosol optical property measurements made at FAN sites are spectral aerosol light scattering (total and backward hemisphere) and light absorption. These are the critical parameters for determining direct aerosol radiative forcing. Most of the sites also measure aerosol number concentration. Depending on the station, additional aerosol and gas-phase measurements may be available. Over the years, NOAA/ GMD has developed protocols and instrument infrastructure in order to make measurements of known high quality, and it has written software to enable consistent processing, editing, and archiving of the data. NOAA (2018b) provides details, design drawings, and photos of the system's components (inlet, instruments, auxiliary control units, pump box, etc.), but brief descriptions of the main components are provided below.

Instruments. Light scattering by atmospheric aerosols at the FAN stations is measured using integrating nephelometers [currently, either the TSI (model 3563, TSI Inc.) or the Ecotech (Aurora 3000/4000, Ecotech) nephelometer]. Both instruments measure total and hemispheric aerosol backscattering coefficients at three visible wavelengths, enabling the calculation of spectral aerosol properties and various proxies describing the angular distribution of light scattering (e.g., Andrews et al. 2006). Table ES1 describes the scattering and absorption instruments at each site. Table ES2 gives further details (e.g., wavelengths) for the various instruments.
Aerosol light absorption is measured at FAN stations using a variety of filter-based absorption instruments. Currently, the primary light absorption instruments are the ESRL/GMD-developed threewavelength continuous light absorption photometer (CLAP; Ogren et al. 2017) and the single-wavelength multiangle absorption photometer (MAAP; Thermo Fisher Scientific). Many sites are also operating seven-wavelength aethalometers (Magee Scientific) to take advantage of that instrument's broad spectral range. Previously, FAN sites used single- and multiwavelength particle soot absorption photometers (PSAP; Radiance Research Inc.) and/or broadband aethalometers.

While the instruments across the FAN are not identical, laboratory studies suggest they make comparable measurements. Intercomparisons of TSI and Ecotech nephelometers show excellent reproducibility for total scattering, although the differences are slightly larger for backscattering (Müller et al. 2011b). Müller et al. (2011a) find good agreement between PSAP and MAAP measurements of aerosol light absorption for a 2007 intercomparison study, although less agreement existed for an earlier (2005) dataset. Müller et al. (2011a) also identify a fairly wide range of variability in PSAPs, but they show much of the variability was due to spot size variations and flow rate issues. The PSAPs and CLAPs in the FAN are corrected for spot size and operated at a consistent flow rate (face velocity of $0.8 \mathrm{~m} \mathrm{~s}^{-1}$ ) to minimize these issues. Ogren et al. (2017) demonstrate excellent agreement between long-term measurements with PSAPs and CLAPs at multiple sites in the FAN. Sherman et al. (2015) present measurement uncertainties for scattering and absorption measurements, as well as for calculated parameters such as single-scattering albedo and the Ångström exponent.

Aerosol number concentration is another common measurement at FAN sites (Table ES3). The most commonly used instruments for this parameter are butanol-based particle counters. Many FAN sites operate multiple particle counters in tandem, which can provide some minimal information on aerosol size distribution because different models have different lower size cuts. Some sites also operate instruments to measure aerosol size distributions (see Table ES3).

Infrastructure and protocols. The FAN is a subset of the WMO Global Atmosphere Watch; consequently, it follows the GAW aerosol guidelines and standard operating procedures (WMO 2011, 2016). The WMO World Calibration Centre for Aerosol Physics (WCCAP; www.wmo-gaw-wcc-aerosol-physics.org/) organizes 
instrument training and evaluation workshops, and performs occasional site audits, which are designed to ensure consistency across the GAW network. The role of the FAN, in this context, is to provide advice and tools that make it easier for station operators to implement the recommended procedures for GAW stations.

The FAN standard aerosol inlet configuration (NOAA 2018c) is slightly anisokinetic (i.e., Reynolds number in the range of 4,500-7,000). The resulting turbulent conditions limit losses of supermicrometer particles (Wilcox 1956). Sampling line sizes, materials, pick-offs, and flow rates are optimized to promote maximum passing efficiency for particles that are most important to radiative forcing (i.e., particles with diameters between 0.1 and $10 \mu \mathrm{m}$ ). Because the focus is primarily on optically important aerosol, bends in tubing and obstructions upstream of instruments are minimized to limit particle losses caused by impaction. Passing efficiencies for supermicron particles are $99 \%$ and $50 \%$ for $1-2$ - and $7-11-\mu \mathrm{m}$ aerodynamic diameter particles, respectively. Different inlet designs and/or instruments should be used for aerosol diameters above this size range. The inlet is not optimized for ultrafine aerosol; however, inlet passing efficiency calculations suggest a $99 \%$ and $50 \%$ passing efficiency for $0.1-$ and $0.002-0.004-\mu \mathrm{m}$ aerodynamic diameter particles, respectively. Figure ES1 in the supplemental materials show the aerosol inlet passing efficiency for several stations. Some collaborators have designed their own inlet system (see Table ES3). WMO (2016) includes guidelines for inlet systems, including criteria and equations used to design them. GAW and FAN offer assistance to station operators with designing inlet systems and calculating losses, but every site is different (e.g., surrounding terrain and vegetation, fog frequency), meaning a common design is not practical or even desirable.

The network goal is to make aerosol measurements at low relative humidity $(\mathrm{RH}<40 \%)$, which minimizes the confounding effects of aerosol amount and hygroscopicity on the optical properties, facilitating a comparison of aerosol properties among FAN sites. This objective is consistent with the wider GAW sampling protocol (WMO 2016). To achieve low RH, two approaches have been used. The first approach involves gentle heating (to a maximum of $40^{\circ} \mathrm{C}$ ) of the sample lines and insulation of the sample lines downstream of the heater. Power is applied to the heater only when the sample humidity is above the desired value. The second approach is to dilute the airstream with dry filtered air generated by a compressor system. The dilution approach is typically used at warm marine sites in the network. The amount of dilution air is measured and corrections to the measurements are applied automatically during data processing.

To fully characterize the sampling system, temperature, $\mathrm{RH}$, flow, and pressure are monitored at several points along the sample line. Monitoring temperature and RH in several places allows determination of whether sample dewpoint temperature is maintained as the air moves through the system. Discrepancies in system dewpoint temperature can indicate a leak in the system (or, possibly, a poorly calibrated sensor). Pressure and flow measurements provide diagnostics to determine whether sample air is flowing through the system as designed. Additionally, both analog and digital flow and pressure measurements are implemented. The analog measurements (rotameters, pressure gauges, etc.) can be assessed at a glance by an on-site operator. The digital measurements are also available to the on-site operator via the data acquisition interface, but they are primarily intended for someone who is remotely evaluating the data.

Many FAN sites make aerosol light scattering and absorption coefficient measurements at two size cuts [aerodynamic particle diameter $<1$ and $<10 \mu \mathrm{m}$ (PM1 and PM10, respectively)]. ESRL/GMD has designed an "impactor box" to smoothly integrate size cut switching into system operations. All sample air flows through a $10-\mu \mathrm{m}$ multijet Berner impactor [Hillamo and Kauppinen (1991) and references therein] prior to being sampled by instruments. On a time base interval ranging from 5 to $30 \mathrm{~min}$, depending on the site, control software closes an automated ball valve, forcing the sample flow through a $1-\mu \mathrm{m}$ Berner impactor. A mass flow controller is used to control flow through the impactors in order to ensure the desired size cut. The impactor box also contains solenoid valves that enable the instruments to be bypassed at certain times (e.g., during impactor cleaning).

The system requires only minor intervention from on-site technicians. Technician tasks include nephelometer calibration gas checks (performed with $\mathrm{CO}_{2}$ and filtered air) to verify instrument calibration (Anderson and Ogren 1998), impactor cleaning, filter changes for the light absorption instruments, and replenishing the operating fluid for number concentration instruments. The frequency of these tasks depends on the site. Most sites perform nephelometer calibration checks and impactor servicing on a weekly to monthly basis, while filter changes and operating fluid replenishment tend to be more frequent. Figure ES2 provides an example of nephelometer calibration checks for FAN sites with at least five years of data. Annually, or whenever problems are suspected, FAN protocols recommend calibration 
of system sensors (temperature $T$, pressure $P, \mathrm{RH}$, flow), cleaning of instruments and sample lines, and overnight filtered air tests on scattering and absorption instruments.

It should be noted that there is currently no calibration standard for filter-based absorption measurements [that is an area of active research, e.g., the European Metrology Programme for Innovation and Research (EMPIR) Black Carbon project (www.empirblackcarbon.com)], but the flows for the absorption instruments are calibrated annually. NOAA/GMD does not utilize a calibration system for particle counters; however, two particle counters are maintained as reference standards, one of which was tested at the WCCAP for connecting the FAN measurements with the wider GAW network. Field condensation particle counters (CPCs) are periodically tested against these laboratory reference CPCs. The CPC flows are also checked on a regular basis. Instrument intercomparisons are a major tool in the in situ aerosol community for ensuring comparable measurements, because of the lack of calibration standards. Additionally, instrument noise evaluations are performed annually for scattering, absorption, and number concentration instruments; these evaluations consist of having the instruments measure filtered air for a $12-24$-h period.

Software. ESRL/GMD has developed custom software (called CPD3) for acquisition, processing, editing, and archiving of data from aerosol instruments that are used in the FAN. More information about the software is available in the supplemental materials but some key aspects are highlighted here. An earlier version of the ESRL/GMD software (CPD2) is also used in the Capacity Building and Twinning for Climate Observing Systems (CATCOS) aerosol network (PSI 2018). The same software suite is used for both field acquisition computers and off-site data processing and analysis. Scientists and technicians responsible for the data use another copy of CPD3 on their desktop or laptop computers to review the data for quality and completeness and flag or remove contaminated or invalid data. The CPD3 system supports direct submission of both near-real-time (raw data) and annual [quality control (QC) reviewed] data to the WMO World Data Centre for Aerosols (WDCA).

CPD3 is highly configurable, making it simple to add or remove instruments at the field site and to change data logging parameters. A list of instruments that can be logged with CPD3 is available from NOAA (2018d). Because all instruments are logged on the same computer using the time server synced computer time stamp, the time stamp for every instrument is the same. Having all the instruments and infrastructure tied together enables the system to operate holistically. For example, if high particle concentrations and/or wind direction indicate local contamination, a contamination flag can be set automatically (e.g., Sheridan et al. 2016). Similarly, chemical filters can be automatically bypassed to avoid sampling contaminated air, while other measurements are flagged (Quinn et al. 2002).

During data review, the ability to inspect multiple data streams simultaneously in a graphical interface helps with identifying both events and troubleshooting system failures. CPD3 includes a time-stamped message log, enabling the data to be directly related to operator actions and observations both on the station computer and after the fact during QC data inspection and editing. CPD3 provides tools for editing and applying standard corrections (e.g., standard temperature and pressure corrections), the truncation correction for the nephelometer (e.g., Anderson and Ogren 1998), various schemes for correcting filter-based absorption measurements (e.g., Bond et al. 1999), and so on. The end result of the integrated software developed at ESRL/GMD is a self-consistent data archive standardized across all stations using the software. Final data from the NOAA/ESRL FAN are available from the WDCA (http://ebas.nilu.no/) for most stations and from the principal investigators (PIs) in all cases.

FAN SCIENCE. While the FAN methodology is useful for a single station, its real strength lies in creating measurement consistency among multiple stations. Science questions that can be addressed with this dataset include the following:

- What are the range and variability (on multiple time scales) of aerosol optical properties observed at FAN sites?

- How do long-term trends in aerosol properties compare across the globe?

By combining FAN data with external datasets, additional questions can be explored, including the following:

- Can similarities and differences among sites be related to aerosol types, sources, or processes?

- How well do global models and aerosol parameterizations in models capture aerosol properties across a range of sites?

- How consistent are the in situ aerosol properties measured at FAN sites with remote sensing 
measurements from ground- and satellite-based instruments, and how do the consistencies and inconsistencies inform interpretation of the results from all three approaches?

Figure 2 illustrates that the FAN sites cover a wide range of aerosol properties. Aerosol loading (e.g., scattering and absorption) spans nearly four orders of magnitude. While scattering at the sites is shown in monotonically increasing order, other aerosol parameters (e.g., single-scattering albedo and scattering Ångström exponent; see Table 1) vary as a function of the nature of the particles (e.g., size, composition) rather than aerosol amount. For example, the clean marine sites-Cape Grim, Australia (CGO); Cape Point, South Africa (CPT); American Samoa (SMO); THD; and Cape San Juan, Puerto Rico (CPR) — exhibit low scattering Ångström exponent (SAE) values indicative of large sea salt aerosol, while the low SAE at Mount Waliguan, China (WLG), can be attributed to large dust particles. Median single-scattering albedo (SSA) values are around 0.92 at most sites, although the clean marine sites exhibit higher SSA values because of predominantly white sea salt aerosol. In contrast, the University of Granada, Granada, Spain (UGR), site exhibits significantly lower SSA relative to the other sites in the FAN-the site is strongly impacted by diesel-based traffic and local biomass burning (Titos et al. 2017). The standardized FAN sampling and data processing protocols help ensure that the reported differences between stations are real and not related to operational inconsistencies. Table ES1 provides more information about the stations and measurement data depicted in Fig. 2.

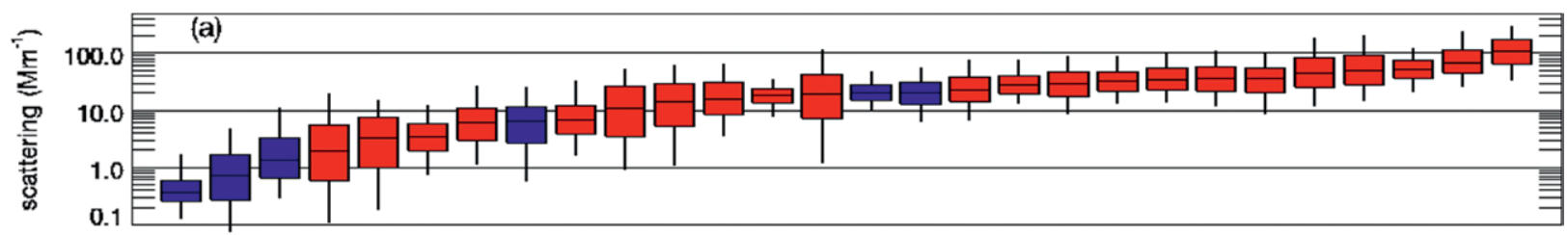

spo sum mlo whi alt cgo spl brw etl beo msa egb cpt lln smo thd app cpr sgp wsa am bnd msy wlg kps ugr gsn amy

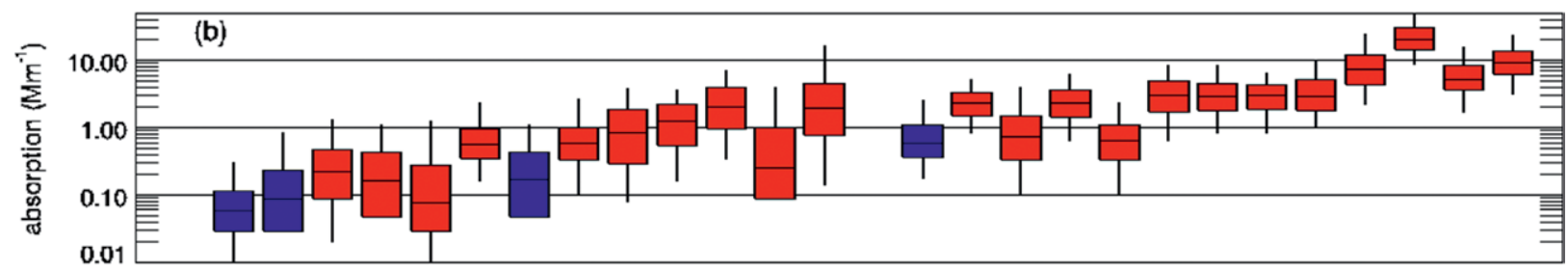

spo sum mlo whi alt cgo spl brw etl beo msa egb cpt In smo thd app cpr sgp wsa am bnd msy wlg kps ugr gsn amy

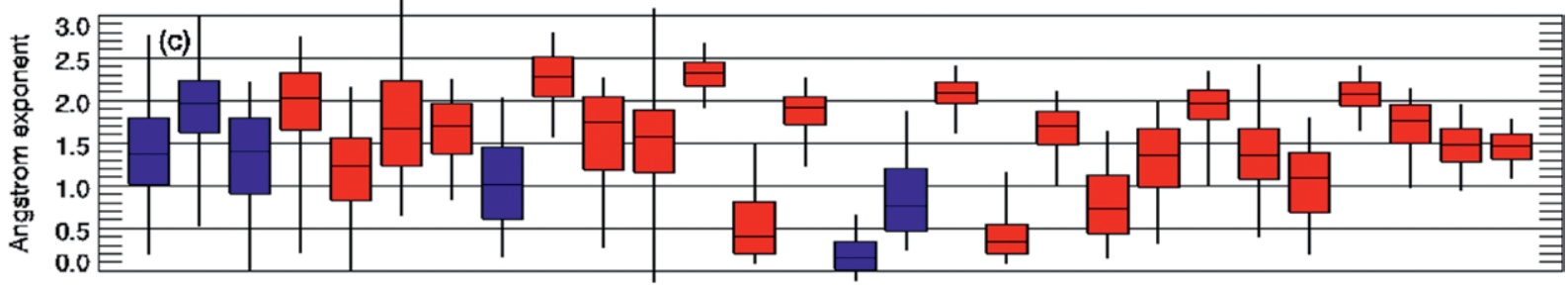

spo sum mlo whi alt cgo spl brw etl beo msa egb cpt Iln smo thd app cpr sgp wsa am bnd msy wlg kps ugr gsn amy

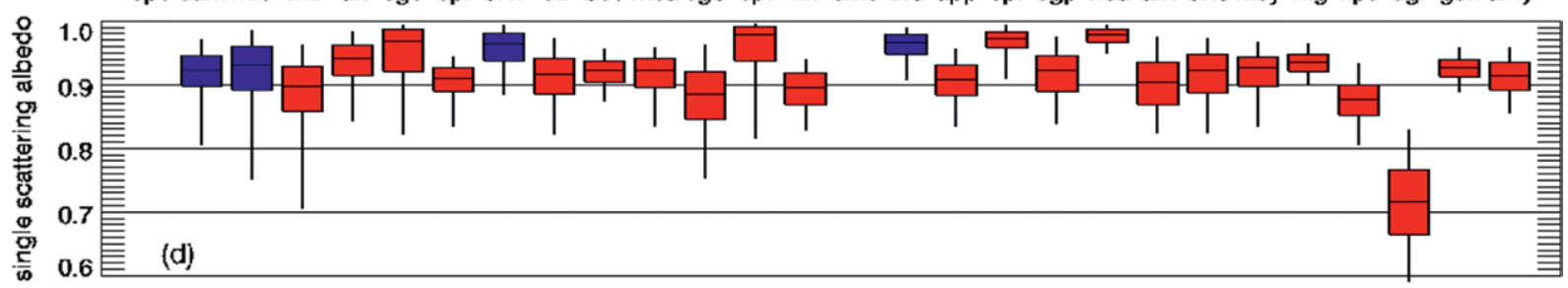

spo sum mlo whi alt cgo spl brw etl beo msa egb cpt lln smo thd app cpr sgp wsa am bnd msy wlg kps ugr gsn amy

Fig. 2. Annual aerosol climatology for long-term sites in the network. Stations are ordered by increasing the scattering coefficient. (a) Scattering coefficient, (b) absorption coefficient, (c) SAE, and (d) SSA. Scattering and absorption have units of inverse megameters $\left(\mathrm{Mm}^{-1}\right)$, and SAE and SSA are unitless. Values are reported at $550 \mathrm{~nm}$, and the SAE is calculated for the blue-green wavelength pair. Whiskers represent 5th and 95th percentiles, edges of each box are 25th and 75th percentiles, and midpoint line in box is the median value of the annual climatology. Blue indicates NOAA observatories, and red indicates collaborator sites. Some sites are not shown because of little available data (e.g., less than a year of data available or data not yet being QC'd). 


\begin{tabular}{|c|c|}
\hline $\begin{array}{l}\text { Aerosol parameter } \\
\quad(\text { symbol) }\end{array}$ & Description of parameter and measurement instrument or equation for calculating \\
\hline Aerosol light scattering $\sigma_{\mathrm{sp}}$ & $\begin{array}{l}\text { Indicator of aerosol amount and related optical effects. Measured in the FAN with an inte- } \\
\text { grating nephelometer. }\end{array}$ \\
\hline Aerosol light absorption $\sigma_{\text {ap }}$ & $\begin{array}{l}\text { Indicator of particle darkness; related to black carbon (BC). Measured in the FAN with a } \\
\text { filter-based absorption photometer. }\end{array}$ \\
\hline $\begin{array}{l}\text { Aerosol number } \\
\text { concentration } N\end{array}$ & $\begin{array}{l}\text { Indicator of local contamination; precursor of cloud condensation nuclei. Measured in the } \\
\text { FAN with a condensation particle counter. }\end{array}$ \\
\hline SAE & $\begin{array}{l}\text { SAE describes the wavelength }(\lambda) \text { dependence of scattered light. When scattering is dominated } \\
\text { by submicrometer particles, the SAE values are typically around } 2 \text {, while SAE values closer to } 0 \\
\text { occur when the scattering is dominated by particles larger than a few micrometers in diameter. } \\
\text { SAE }=-\log \left[\sigma_{\text {sp }}\left(\lambda_{1}\right) / \sigma_{\text {sp }}\left(\lambda_{2}\right)\right] / \log \left(\lambda_{2} / \lambda_{1}\right)\end{array}$ \\
\hline SSA & $\begin{array}{l}\text { SSA describes the relative contributions of scattering and absorption to the total light extinc- } \\
\text { tion. Purely scattering aerosols (e.g., sulfuric acid) have SSA values of I, while very strong } \\
\text { absorbers (e.g., elemental carbon) have SSA values around } 0.3 \text {. } \\
\text { SSA }=\sigma_{\mathrm{sp}} /\left(\sigma_{\mathrm{sp}}+\sigma_{\mathrm{ap}}\right)\end{array}$ \\
\hline
\end{tabular}

Figures ES3-ES5 show the same data depicted in Fig. 2 in separate sets of panes with aerosol scattering coefficient ordered by elevation (Fig. ES3), latitude (Fig. ES4), and longitude (Fig. ES5).

While Fig. 2 shows annual climatological values for all sites in the network, more detailed climatologies can be evaluated as well. Figure 3 shows climatological patterns of aerosol light scattering at Bondville as a function of year, month, and day of year. Figure $3 \mathrm{a}$ shows that there has been a decrease in aerosol light scattering at Bondville since the start of measurements in the mid-1990s and that this decrease appears to have impacted scattering during all months at the site. This result is consistent with other literature documenting decreases in aerosol loading over most of the continental United States (e.g., Collaud Coen et al. 2013). Although aerosol amounts have decreased over the last two decades, the general picture of higher scattering during the summer remains true. Figure $3 \mathrm{~b}$ depicts how the diurnal cycle varies with time of year. In the summer, the scattering is high throughout the day, while at other times of year the diurnal cycle is much more pronounced [similar to the observations of Sherman et al. (2015)]. The diurnal minimum occurs in the early afternoon, most likely as a result of an increase in boundary layer height.

Detailed multisite climatologies, including data from FAN observatories, based on location [e.g., mountain sites (Andrews et al. 2011); North American sites (e.g., Sherman et al. 2015; Delene and Ogren 2002); and Arctic sites (Schmeisser et al. 2018)] have been published. Sites in the FAN are often members of other networks [e.g., European Research Infrastructure for the Observation of Aerosol, Clouds, and Trace Gases
(ACTRIS), www.actris.eu/; International Arctic Systems for Observing the Atmosphere (IASOA), www .esrl.noaa.gov/psd/iasoa/] and are included in reports on their climatologies as well (e.g., Uttal et al. 2016; Zanatta et al. 2016; Pandolfi et al. 2018). Additionally, with multiple sites one can look at the covariability of different aerosol properties and start to identify relationships as a function of site and aerosol type (e.g., Delene and Ogren 2002; Andrews et al. 2011; Sherman et al. 2015; Schmeisser et al. 2017). Trend studies have also used data from multiple FAN sites as the focus of their investigation (e.g., Asmi et al. 2013; Collaud Coen et al. 2013; Sherman et al. 2015) to explore changes in aerosol properties as a function of location.

An additional advantage of the unified FAN dataset is that it can be used to assess and improve global models. Multiple studies use FAN number concentration data to evaluate various parameterizations of aerosol nucleation (e.g., Spracklen et al. 2010; Matsui et al. 2013; Mann et al. 2014; Yu and Hallar 2014). Skeie et al. (2011) evaluated how well the Oslo Chemical Transport Model, version 2 (CTM2), simulated absorbing aerosol in terms of loading and seasonality at multiple FAN stations. There are several modeling studies using Arctic sites FAN data. For example, Sharma et al. (2013) explored the sensitivity of absorbing aerosol to wet and dry deposition, while Eckhardt et al. (2015) used Arctic surface measurements to evaluate simulated model climatologies. Currently, the FAN data are being utilized to evaluate Aerosol Comparisons between Observations and Models (AeroCom; Kinne et al. 2006) global model simulations of surface aerosol scattering and absorption coefficients (E. Andrews et al. 2019, unpublished manuscript). 

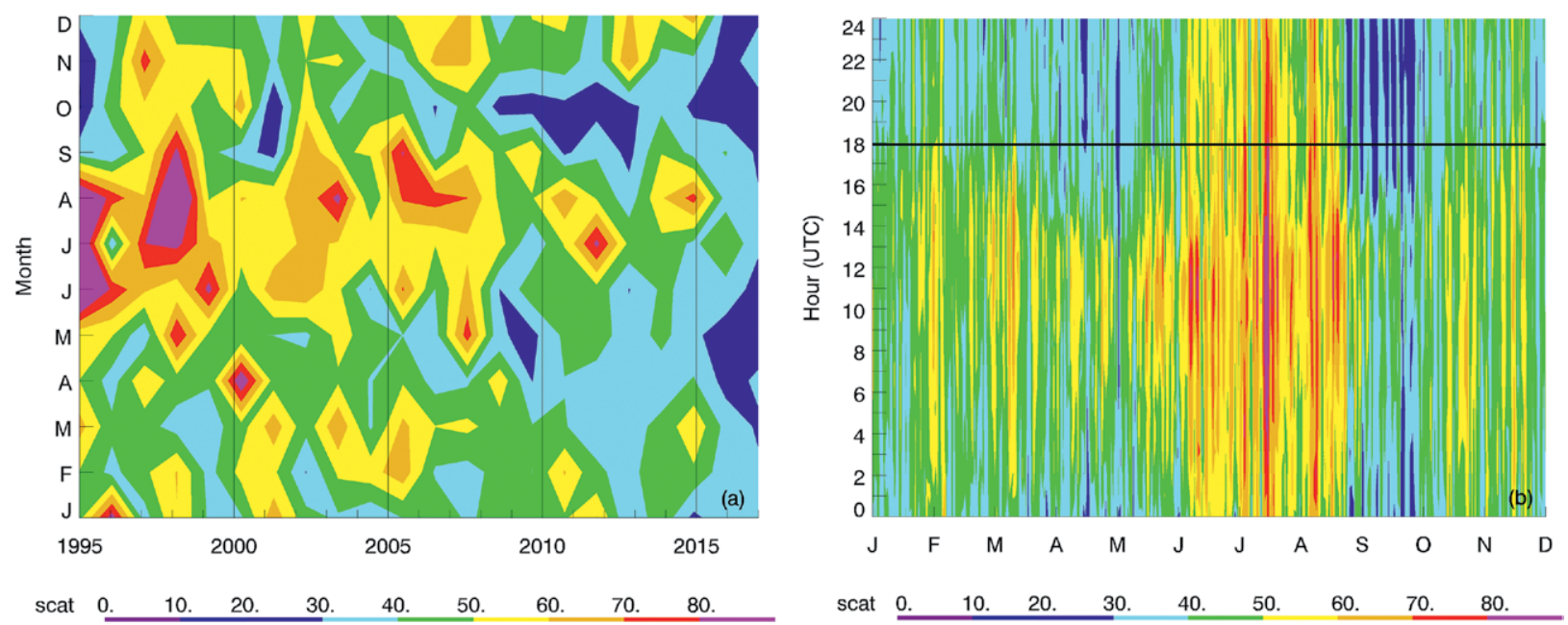

FIG. 3. Long-term climatology of aerosol light scattering (at $550 \mathrm{~nm}$; $\mathbf{M m}^{-1}$ ) at Bondville. (a) Monthly variability as a function of year. (b) Diurnal variability as a function of month (thick black horizontal line indicates local noon). Both plots are based on data obtained from 1995 through 2016.

While the FAN data consistency allows for collective science using data from multiple sites, the unique locations and interests of scientists involved with each site have also resulted in many findings. For example, there have been both climatological and transport event-based studies focused on aerosol types observed at individual sites (e.g., Lim et al. 2012; Hallar et al. 2015; Sorribas et al. 2015, 2017; Denjean et al. 2016; H. Rivera et al. 2018, unpublished manuscript; Kassianov et al. 2017). FAN measurements have been used to provide context for field campaigns (e.g., Brock et al. 2011; Bravo-Aranda et al. 2015; Denjean et al. 2016), instrument comparisons (e.g., Sharma and Barnes 2016; Backman et al. 2017; Sinha et al. 2017; Sharma et al. 2017), remote sensing validation (e.g., Pahlow et al. 2006; Di Pierro et al. 2013; Shinozuka et al. 2015), direct aerosol radiative forcing sensitivities and uncertainties (e.g., Sherman and McComiskey 2018), and many other scientific efforts.

Uniting observatories under the umbrella of the Federated Aerosol Network provides the opportunity to both train and learn from a diverse group of U.S. and international partners. The federated nature of the network enables scientists to pursue their own interests while participating in a wider goal, making the network greater than the sum of its individual parts. In the process of increasing understanding of the range and variability in aerosol radiative properties, the FAN strengthens scientific ties across the globe, fostering collaborations and the exchange of knowledge. In the FAN's next 25 years, the objective is to maintain current collaborations and to establish new ones to expand the network, particularly in undersampled regions. The FAN will continue to improve measurements, software, and protocols in order to be able to address new questions as they arise. For example, in the future, a complementary network composed of new low-cost sensors could be developed or even used to expand the FAN or other networks pending guidance from WMO GAW (e.g., WMO 2018).

CONCLUSIONS. The FAN is a long-term cooperative program enabling diverse sites with a wide range of aerosol types to make measurements that are directly comparable with other network stations. This facilitates the exploration of science questions at local, regional, and global scales, and makes the network measurements especially useful for global model evaluation. There is a need to expand such measurements to locations that have large impacts by aerosols but little current representation in measurement databases; however, many factors (e.g., funding), of course, will determine whether this really takes place. The growth and scope of NOAA's collaborative network can be a model for new and existing networks that seek to expand coverage in a collaborative fashion.

ACKNOWLEDGMENTS. The writing of this manuscript was supported by the NOAA Climate Program Office's Atmospheric Chemistry, Carbon Cycle, and Climate (AC4) program. The FAN would not be possible without the interest and support of our collaborators and their students, and/or technicians, who maintain the stations and instruments, and keep the data flowing from their observatories and the funding from myriad sources for each site ensuring continued site operations. 
Charlson, R. J., J. Langner, H. Rodhe, C. B. Leovy, and S. G. Warren, 1991: Perturbation of the northern hemisphere radiative balance by backscattering from anthropogenic sulfate aerosols. Tellus, 43AB, 152-163, https://doi.org/10.1034/j.1600-0870.1991.00013.x. integrating nephelometer. Aerosol Sci. Technol., 29, 57-69, https://doi.org/10.1080/02786829808965551.

_ , and Coauthors, 2005: An "A-Train" strategy for quantifying direct climate forcing by anthropogenic aerosols. Bull. Amer. Meteor. Soc., 86, 1795-1809, https://doi.org/10.1175/BAMS-86-12-1795.

Andrews, E., P. J. Sheridan, J. A. Ogren, and R. Ferrare, 2004: In situ aerosol profiles over the Southern Great Plains cloud and radiation testbed site: 1 . Aerosol optical properties. J. Geophys. Res., 109, D06208, https://doi.org/10.1029/2003JD004025.

_ - and Coauthors, 2006: Comparison of methods for deriving aerosol asymmetry parameter. J. Geophys. Res., 111, D05S04, https://doi.org/10.1029 /2004JD005734.

— , and Coauthors, 2011: Climatology of aerosol radiative properties in the free troposphere. Atmos. Res., 102, 365-393, https://doi.org/10.1016/j.atmosres .2011.08.017.

Asmi, A., and Coauthors, 2013: Aerosol decadal trends-Part 2: In-situ aerosol particle number concentrations at GAW and ACTRIS stations. Atmos. Chem. Phys., 13, 895-916, https://doi.org/10.5194 /acp-13-895-2013.

Backman, J., and Coauthors, 2017: On aethalometer measurement uncertainties and multiple scattering enhancement in the Arctic. Atmos. Meas. Tech., 10, 5039-5062, https://doi.org/10.5194/amt-10-5039-2017.

Bodhaine, B. A., 1983: Aerosol measurements at four background sites. J. Geophys. Res., 88, 10753-10 768, https://doi.org/10.1029/JC088iC15p10753.

Bolin, B., and R. J. Charlson, 1976: On the role of the tropospheric sulfur cycle in the shortwave radiative climate of the Earth. Ambio, 3, 47-54.

Bond, T. C., T. L. Anderson, and D. Campbell, 1999: Calibration and intercomparison of filter-based measurements of visible light absorption by aerosols. Aerosol Sci. Technol., 30, 582-600, https://doi .org/10.1080/027868299304435.

Bravo-Aranda, J. A., and Coauthors, 2015: Study of mineral dust entrainment in the planetary boundary layer by lidar depolarisation technique. Tellus, 67B, 262180, https://doi.org/10.3402/tellusb.v67.26180.

Brock, C. A., and Coauthors, 2011: Characteristics, sources, and transport of aerosols measured in spring 2008 during the aerosol, radiation, and cloud processes affecting Arctic Climate (ARCPAC) Project. Atmos. Chem. Phys., 11, 2423-2453, https://doi .org/10.5194/acp-11-2423-2011.

Collaud Coen, M., and Coauthors, 2013: Aerosol decadal trends-Part 1: In-situ optical measurements at GAW and IMPROVE stations. Atmos. Chem. Phys., 13, 869-894, https://doi.org/10.5194/acp -13-869-2013.

Delene, D. J., and J. A. Ogren, 2002: Variability of aerosol optical properties at four North American surface monitoring sites. J. Atmos. Sci., 59, 1135-1150, https:// doi.org/10.1175/1520-0469(2002)059<1135:VOAOP A $>2.0 . \mathrm{CO} ; 2$.

Denjean, C., and Coauthors, 2016: Size distribution and optical properties of African mineral dust after intercontinental transport. J. Geophys. Res. Atmos., 121, 7117-7138, https://doi.org/10.1002/2016JD024783.

Di Pierro, M., L. Jaegle, E. W. Eloranta, and S. Sharma, 2013: Spatial and seasonal distribution of Arctic aerosols observed by the CALIOP satellite instrument (2006-2012). Atmos. Chem. Phys., 13, 7075-7095, https://doi.org/10.5194/acp-13-7075-2013.

Eckhardt, S., and Coauthors, 2015: Current model capabilities for simulating black carbon and sulfate concentrations in the Arctic atmosphere: A multi-model evaluation using a comprehensive measurement data set. Atmos. Chem. Phys., 15, 9413-9433, https://doi .org/10.5194/acp-15-9413-2015.

Hallar, A. G., R. Petersen, E. Andrews, J. Michalsky, I. McCubbin, and J. A. Ogren, 2015: Contributions of dust and biomass burning to aerosols at a Colorado mountain-top site. Atmos. Chem. Phys., 15, 1366513679, https://doi.org/10.5194/acp-15-13665-2015.

Hillamo, R. E., and E. I. Kauppinen, 1991: On the performance of the Berner low pressure impactor. Aerosol Sci. Technol., 14, 33-47, https://doi.org /10.1080/02786829108959469.

Holben, B. N., and Coauthors, 1998: AERONET-A federated instrument network and data archive for aerosol characterization. Remote Sens. Environ., 66, 1-16, https://doi.org/10.1016/S0034-4257(98)00031-5. IPCC, 2013: Climate Change 2013: The Physical Science Basis. Cambridge University Press, 1535 pp., https:// doi.org/10.1017/CBO9781107415324.

Kahn, R. A., and Coauthors, 2004: Aerosol data sources and their roles within PARAGON. Bull. Amer. Meteor. Soc., 85, 1511-1522, https://doi.org/10.1175 /BAMS-85-10-1511.

—, and Coauthors, 2017: SAM-CAAM: A concept for acquiring systematic aircraft measurements to characterize aerosol air masses. Bull. Amer. Meteor. 
Soc., 98, 2215-2228, https://doi.org/10.1175/BAMS -D-16-0003.1.

Kassianov, E., and Coauthors, 2017: Large contribution of coarse mode to aerosol microphysical and optical properties: Evidence from ground-based observations of a transpacific dust outbreak at a high-elevation North American site. J. Atmos. Sci., 74, 1431-1443, https://doi.org/10.1175/JAS -D-16-0256.1.

Kinne, S., and Coauthors, 2006: An AeroCom initial assessment-Optical properties in aerosol component modules of global models. Atmos. Chem. Phys., 6, 1815-1834, https://doi.org/10.5194/acp -6-1815-2006.

Kulmala, M., and Coauthors, 2011: General overview: European Integrated project on Aerosol Cloud Climate and Air Quality Interactions (EUCAARI) - Integrating aerosol research from nano to global scales. Atmos. Chem. Phys., 11, 13 061-13 143, https://doi .org/10.5194/acp-11-13061-2011.

Laj, P., and Coauthors, 2009: Measuring atmospheric composition change. Atmos. Environ., 43, 5351-5414, https://doi.org/10.1016/j.atmosenv.2009.08.020.

Lim, S., M. Lee, G. Lee, S. Kim, and K. Kang, 2012: Ionic and carbonaceous compositions of PM10, PM2.5 and PM1.0 at Gosan ABC Superstation and their ratios as source signature. Atmos. Chem. Phys., 12, 2007-2024, https://doi.org/10.5194/acp-12-2007-2012.

Lund Myhre, C., and U. Baltensperger, 2012: Recommendations for a composite surface-based aerosol network. WMO GAW Rep. 207, 58 pp., http://library .wmo.int/pmb_ged/gaw_207.pdf.

Mann, G. W., and Coauthors, 2014: Intercomparison and evaluation of global aerosol microphysical properties among AeroCom models of a range of complexity. Atmos. Chem. Phys., 14, 4679-4713, https://doi.org/10.5194/acp-14-4679-2014.

Matsui, H., and Coauthors, 2013: Spatial and temporal variations of new particle formation in East Asia using an NPF-explicit WRF-chem model: Northsouth contrast in new particle formation frequency. J. Geophys. Res. Atmos., 118, 11647-11 663, https:// doi.org/10.1002/jgrd.50821.

Müller, T., and Coauthors, 2011a: Characterization and intercomparison of aerosol absorption photometers: Result of two intercomparison workshops. Atmos. Meas. Tech., 4, 245-268, https://doi.org/10.5194 /amt-4-245-2011.

_- M. Laborde, G. Kassell, and A. Wiedensohler, 2011b: Design and performance of a three-wavelength LEDbased total scatter and backscatter integrating nephelometer. Atmos. Meas. Tech., 4, 1291-1303, https:// doi.org/10.5194/amt-4-1291-2011.
NOAA, 2018a: Network publications. Accessed 21 May 2018, ftp://aftp.cmdl.noaa.gov/aerosol/doc/newsletter /publications.html.

— 2018 b: ESRL/GMD aerosol measurements. Accessed 21 May 2018, www.esrl.noaa.gov/gmd/aero /instrumentation/instrum.html.

- 2018c: Aerosol system inlet. Accessed 21 May 2018, www.esrl.noaa.gov/gmd/aero/instrumentation/ inlet_system.html.

— 2018d: CPD3 loggable instruments. Accessed 21 May 2018, www.esrl.noaa.gov/gmd/aero/instrumentation /cpd_inst.html.

Ogren, J. A., 1995: A systematic approach to in situ observation of aerosol properties. Aerosol Forcing of Climate: Report of the Dahlem Workshop on Aerosol Forcing of Climate, R. Charlson and J. Heintzenberg, Eds., Environmental Sciences Research Report, Vol. ES 17, John Wiley \& Sons, Ltd., 215-226.

—, J. Wendell, E. Andrews, and P. Sheridan, 2017: Continuous light absorption photometer for longterm studies. Atmos. Meas. Tech., 10, 4805-4818, https://doi.org/10.5194/amt-10-4805-2017.

Pahlow, M., and Coauthors, 2006: Comparison between lidar and nephelometer measurements of aerosol hygroscopicity at the Southern Great Plains Atmospheric Radiation Measurement site. J. Geophys. Res., 111, D05S15, https://doi.org/10.1029/2004JD005646.

Pandolfi, M., and Coauthors, 2018: A European aerosol phenomenology-6: Scattering properties of atmospheric aerosol particles from 28 ACTRIS sites. Atmos. Chem. Phys., 18, 7877-7911, https:/doi .org/10.5194/acp-18-7877-2018.

Perry, K. D., T. A. Cahill, R. C. Schnell, and J. M. Harris, 1999: Long-range transport of anthropogenic aerosols to the National Oceanic and Atmospheric Administration baseline station at Mauna Loa Observatory, Hawaii. J. Geophys. Res., 104, 18521-18533, https://doi.org/10.1029/1998JD100083.

PSI, 2018: CATCOS aerosol measurements. Accessed 21 May 2018, www.psi.ch/catcos/.

Quinn, P. K., T. L. Miller, T. S. Bates, J. A. Ogren, E. Andrews, and G. E. Shaw, 2002: A 3-year record of simultaneously measured aerosol chemical and optical properties at Barrow, Alaska. J. Geophys. Res., 107, 4130, https://doi.org/10.1029/2000JD000037.

Schmeisser, L., and Coauthors, 2017: Classifying aerosol type using in situ surface spectral aerosol optical properties. Atmos. Chem. Phys., 17, 12 097-12 120, https://doi.org/10.5194/acp-17-12097-2017.

_ , and Coauthors, 2018: Seasonality of aerosol optical properties in the Arctic. Atmos. Chem. Phys., 18, 11 599-11 622, https://doi.org/10.5194/acp-18 -11599-2018. 
Sharma, N. C. P., and J. E. Barnes, 2016: Boundary layer characteristics over a high altitude station, Mauna Loa Observatory. Aerosol Air Qual. Res., 16, 729-737, https://doi.org/10.4209/aaqr.2015.05.0347.

Sharma, S., M. Ishizawa, D. Chan, D. Lavoué, E. Andrews, K. Eleftheriadis, and S. Maksyutov, 2013: 16-year simulation of Arctic black carbon: Transport, source contribution, and sensitivity analysis on deposition. J. Geophys. Res. Atmos., 118, 943-964, https://doi .org/10.1029/2012JD017774.

— , and Coauthors, 2017: An evaluation of three methods for measuring black carbon at Alert, Canada. Atmos. Chem. Phys., 17, 15225-15243, https://doi .org/10.5194/acp-17-15225-2017.

Sheridan, P. J., D. J. Delene, and J. A. Ogren, 2001: Four years of continuous surface aerosol measurements from the Department of Energy's Atmospheric Radiation Measurement Program Southern Great Plains Cloud and Radiation Testbed site. J. Geophys. Res., 106, 20 735-20 747, https://doi .org/10.1029/2001JD000785.

—, E. Andrews, J. A. Ogren, J. Tackett, and D. M. Winker, 2012: Vertical profiles of aerosol optical properties over central Illinois and comparison with surface and satellite measurements. Atmos. Chem. Phys., 12, 11 695-11 721, https://doi.org/10.5194 /acp-12-11695-2012.

,,-- L. Schmeisser, B. Vasel, and J. A. Ogren, 2016: Aerosol measurements at South Pole: Climatology and impact of local contamination. Aerosol Air Qual. Res., 16, 855-872, https://doi.org/10.4209 laaqr.2015.05.0358.

Sherman, J. P., and A. McComiskey, 2018: Measurementbased climatology of aerosol direct radiative effect, its sensitivities, and uncertainties from a background southeast U.S. site. Atmos. Chem. Phys., 18, 4131-4152, https://doi.org/10.5194/acp-18-4131-2018.

— , P. J. Sheridan, J. A. Ogren, E. Andrews, D. C. Hageman, L. Schmeisser, A. Jefferson, and S. Sharma, 2015: A multi-year study of lower tropospheric aerosol variability and systematic relationships from four North American regions. Atmos. Chem. Phys., 15, 12 487-12 517, https://doi.org/10.5194/acp-15 $-12487-2015$.

Shinozuka, Y., and Coauthors, 2015: The relationship between cloud condensation nuclei (CCN) concentration and light extinction of dried particles: Indications of underlying aerosol processes and implications for satellite-based CCN estimates. Atmos. Chem. Phys., 15, 7585-7604, https://doi.org/10.5194 lacp-15-7585-2015.

Sinha, P. R., and Coauthors, 2017: Evaluation of groundbased black carbon measurements by filter-based photometers at two Arctic sites. J. Geophys. Res. Atmos., 122, 3544-3572, https://doi.org/10.1002 /2016JD025843.

Skeie, R. B., T. Berntsen, G. Myhre, J. A. Pedersen, J. Strom, S. Gerland, and J. A. Ogren, 2011: Black carbon in the atmosphere and snow, from pre-industrial times until present. Atmos. Chem. Phys., 11, 68096836, https://doi.org/10.5194/acp-11-6809-2011.

Sorribas, M., J. A. Ogren, F. J. Olmo, A. Quirantes, R. Fraile, M. Gil-Ojeda, and L. Alados-Arboledas, 2015: Assessment of African desert dust episodes over the southwest Spain at sea level using in situ aerosol optical and microphysical properties. Tellus, 67B, 27482, https://doi.org/10.3402/tellusb.v67.27482.

—, E. Andrews, J. A. Adame, and M. Yela, 2017: An anomalous African dust event and its impact on aerosol radiative forcing on the Southwest Atlantic coast of Europe in February 2016. Sci. Total Environ., 583, 269-279, https://doi.org/10.1016/j .scitotenv.2017.01.064.

Spracklen, D. V., and Coauthors, 2010: Explaining global surface aerosol number concentrations in terms of primary emissions and particle formation. Atmos. Chem. Phys., 10, 4775-4793, https://doi.org/10.5194 /acp-10-4775-2010.

Stone, R. S., G. P. Anderson, E. Andrews, E. G. Dutton, E. P. Shettle, and A. Berk, 2007: Incursions and radiative impact of Asian dust in northern Alaska. Geophys. Res. Lett., 34, L14815, https://doi.org /10.1029/2007GL029878.

Titos, G., and Coauthors, 2017: Spatial and temporal variability of carbonaceous aerosols: Assessing the impact of biomass burning in the urban environment. Sci. Total Environ., 578, 613-625, https://doi .org/10.1016/j.scitotenv.2016.11.007.

Uttal, T., and Coauthors, 2016: International Arctic Systems for Observing the Atmosphere: An International Polar Year legacy consortium. Bull. Amer. Meteor. Soc., 97, 1033-1056, https://doi.org/10.1175 /BAMS-D-14-00145.1.

Wang, R., and Coauthors, 2018: Representativeness error in the ground-level observation networks for black carbon radiation absorption. Geophys. Res. Lett., 45, 2106-2114, https://doi.org/10.1002/2017GL076817.

Wiedensohler, A., and Coauthors, 2012: Mobility particle size spectrometers: Harmonization of technical standards and data structure to facilitate high quality long-term observations of atmospheric particle number size distributions. Atmos. Meas. Tech., 5, 657-685, https://doi.org/10.5194/amt-5-657-2012.

Wilcox, J. D., 1956: Isokinetic flow and sampling. J. Air Pollut. Control Assoc., 5, 226-245, https://doi.org/10 $.1080 / 00966665.1956 .10467715$. 
WMO, 2011: WMO/GAW standard operating procedures for in-situ measurements of aerosol mass concentration, light scattering and light absorption. World Meteorological Organization GAW Rep. 200, 130 pp., http://library.wmo.int/pmb_ged/gaw_200.pdf.

—, 2016: WMO/GAW aerosol measurement procedures, guidelines, and recommendations. 2nd ed. World Meteorological Organization GAW Rep. 227, 93 pp., https://library.wmo.int/opac/doc_num .php?explnum_id=3073.

_ 2018: Low-cost sensors for the measurement of atmospheric composition: Overview of topic and future applications. A. C. Lewis, E. von Schneidemesser, and R. E. Peltier, Eds., WMO Rep. 1215, 46 pp., www.wmo.int/pages/prog/arep/gaw/documents /Low_cost_sensors_post_review_final.pdf.

Yu, F., and A. G. Hallar, 2014: Difference in particle formation at a mountaintop location during spring and summer: Implications for the role of sulfuric acid and organics in nucleation. J. Geophys. Res. Atmos., 119, 12246-12 255, https://doi.org/10.1002/2014JD022136.

Zanatta, M., and Coauthors, 2016: A European aerosol phenomenology-5: Climatology of black carbon optical properties at 9 regional background sites across Europe. Atmos. Environ., 145, 346-364, https://doi .org/10.1016/j.atmosenv.2016.09.035.

\section{FROM AMS BOOKS}

\section{"A thoughtful analysis of actions that we need to take to reduce the impacts of extreme weather... a must-read for everyone with an interest in the weather and climate." \\ - FRANKLIN W. NUTTER, \\ President, Reinsurance Association of America}

\section{Living on the Real World: How Thinking and Acting Like Meteorologists Will Help Save the Planet}

WILLIAM H. HOOKE

Meteorologists sift through a deluge of information to make predictions every day. Instead of being overwhelmed by the data and possibilities, they focus on small bits of information while using frequent collaboration to make decisions. With climate change a reality, William H. Hooke suggests we look to the way meteorologists operate as a model for how we can solve the twenty-first century's most urgent environmental problems. 

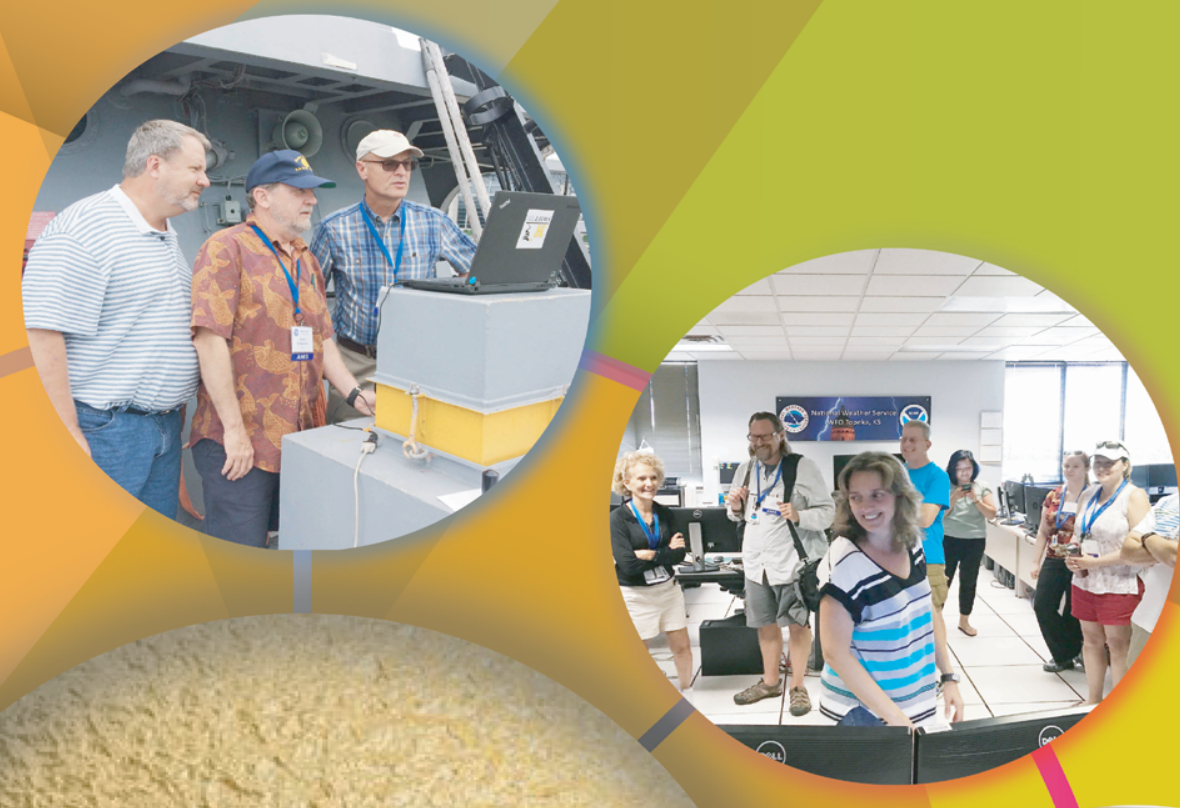

\section{ams EDUICATION}

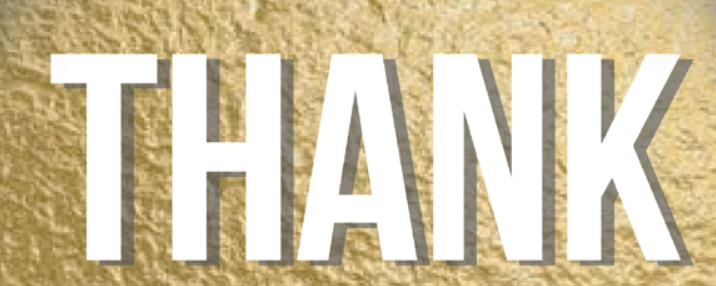

stit 